roneous diagnosis may be reached, resulting in inappropriate investigation and treatment. The diagnostic difficulties may be further compounded in small bone marrow trephine biopsy specimens where the usual follicular growth pattern of these lymphomas may not be appreciated. In the present case the initial favoured morphological diagnosis was metastatic signet-ring adenocarcinoma and a diagnosis of lymphoma was only reached after the histochemical and immunohistochemical results became available. Electron microscopy may also help by showing lymphoid features and an absence of epithelial or melanocytic differentiation.

1 Talbot DC, Davies JH, MacLennan KA, Smith IE. Signetring cell lymphoma of bone marrow. $\mathcal{f}$ Clin Pathol 1994; 47:184-6.

2 Kim H, Dorfman RF, Rappaport H. Signet-ring cell lymph- oma: a rare morphological and functional expression of nodular (follicular) lymphoma. Am $\mathcal{F}$ Surg Pathol 1978;2: 119-32.

3 Silberman S, Fresco R, Steinecker PH. Signet-ring cell lymphoma: a report of a case and review of the literature. lymphoma: a report of a case and

4 Harris M, Eyden B, Read G. Signet-ring cell lymphoma: a rare variant of follicular lymphoma. $\mathcal{F}$ Clin Pathol 1981; 34:884-91.

5 Cross PA, Eyden BP, Harris M. Signet-ring cell lymphoma of T-cell type. $\mathcal{F}$ Clin Pathol 1989;42:239-45.

6 Weiss LM, Wood GS, Dorfman RF. T-cell signet-ring cell lymphoma: a histologic, ultrastructural and immunohistochemical study of two cases. Am $\mathcal{f}$ Surg Pathol 1985 9:273-80.

7 Grogan TM, Payne CM, Richter LC, Rangel CS. Signetring cell lymphoma of T-cell origin: an immunocytochemical and ultrastructural study relating giant vacytochemical and ultrastructural study relating giant vamembrane. Am f Surg Pathol 1985;9:684-92.

8 Tungekar MF. Gastric signet-ring cell lymphoma with alpha heavy chains. Histophathology 1986;10:725-33.

9 Allevato PA, Kini SR, Rebuck JW, Miller JM, Hamburger $\mathrm{J}$. Signet-ring cell lymphoma of the thyroid: a case report. Hum Pathol 1985;16:1066-8.

10 Stramignoni A, Palestro G, Coda R, Micca FB, Stramignoni D. Signet-ring cell lymphoma in salivary gland: an immunohistochemical and ultrastructural study. Appl Pathol 1984;2:76-84.

\title{
Degenerative changes in myometrium simulating diffuse leiomyomatosis after treatment with gonadotrophin releasing hormone analogue
}

\author{
M Jeffers, C Cowan, C B Lunan
}

\begin{abstract}
Degenerative changes are encountered relatively frequently in uterine leiomyomas. Morphologic changes within leiomyomas, particularly necrosis and alterations in cellularity, have been described following treatment with gonadotrophin releasing hormone analogue, but the effects of this form of treatment on the morphology of the normal myometrium are less well documented. A case is reported of a 42 year old woman with a history of menorrhagia in whom a combination of degenerative and iatrogenic changes resulted in a histological appearance resembling diffuse leiomyomatosis.

(f Clin Pathol 1995;48:278-280)
\end{abstract}

Keywords: Leiomyomatosis, gonadotrophin releasing hormone analogue.

Gonadotrophin releasing hormone ( $\mathrm{GnRH}$ ) analogues are used in the management of patients with uterine leiomyomas. Reduction in leiomyoma volume occurs following
GnRH analogue administration, possibly because of atrophy of smooth muscle cells. ${ }^{1}$ Changes in cellularity, necrosis, and haemorrhage have been described in leiomyomas following treatment with $\mathrm{GnRH}$ analogues, ${ }^{1-4}$ but the range of histopathological changes resulting from the administration of GNRH analogues has yet to be fully defined. Here, we report a case in which features suggestive of diffuse leiomyomatosis were present in a hysterectomy specimen following administration of goserelin, a GnRH analogue.

\section{Case report}

A 42 year old woman had been attending the gynaecology clinic for four years with a history of menorrhagia. Examination at initial presentation revealed a small mobile uterus. She was started on a cyclical progestogen but defaulted from follow-up. Two years later, the patient presented with acute urinary retention and was found to have an enlarged uterus with fibroids. She also complained of menorrhagia; endometrial curretage was performed yielding normal secretory endometrium. She was started on a progesterone 


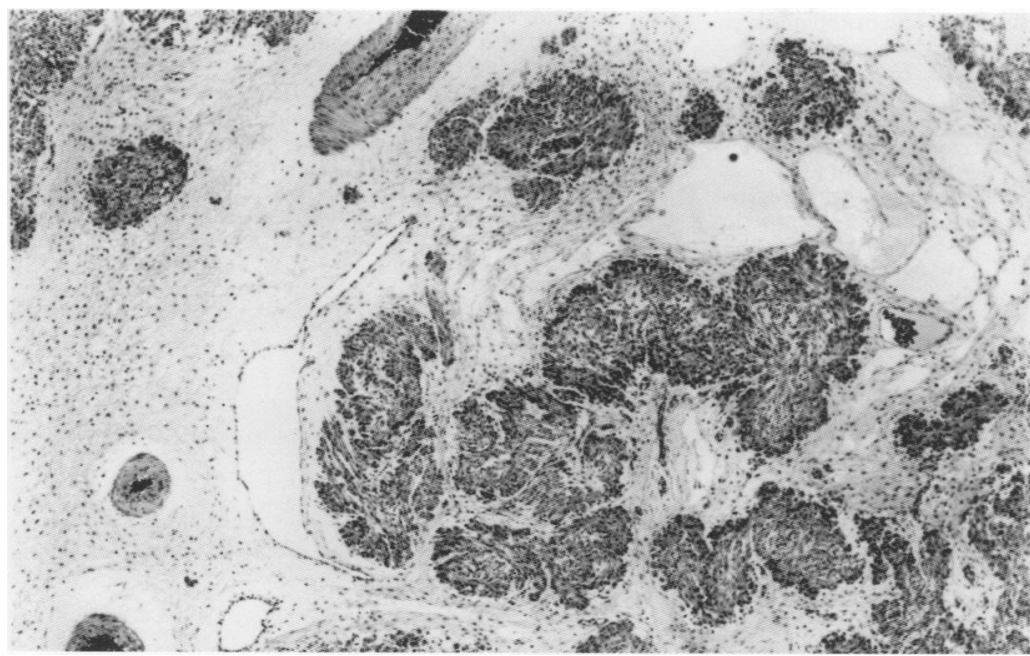

Figure 1 Perinodular degeneration within a leiomyoma.

only pill with little improvement in menstrual symptoms and after six months, this was changed to a low dose combined pill with reasonable success. Eight months later, the patient was admitted as an emergency with menorrhagia and a cervical polyp. Polypectomy was performed and a polypoid adenomyoma removed. Hysteroscopy four months later revealed multiple fibroids. She was started on goserelin and norethisterone and achieved good control of bleeding. Hysterectomy was performed three months later.

The uterus weighed $630 \mathrm{~g}$ and measured $12 \times 14 \times 8.5 \mathrm{~cm}$. Multiple fibroids ranging in size from 0.5 to $6.5 \mathrm{~cm}$ in diameter were present in submucosal and intramural locations. The larger fibroids showed degeneration with cystic areas partially filled by innumerable small nodules of smooth muscle up to $0.3 \mathrm{~cm}$ in diameter. There were also several ill-defined abnormal white areas pre-

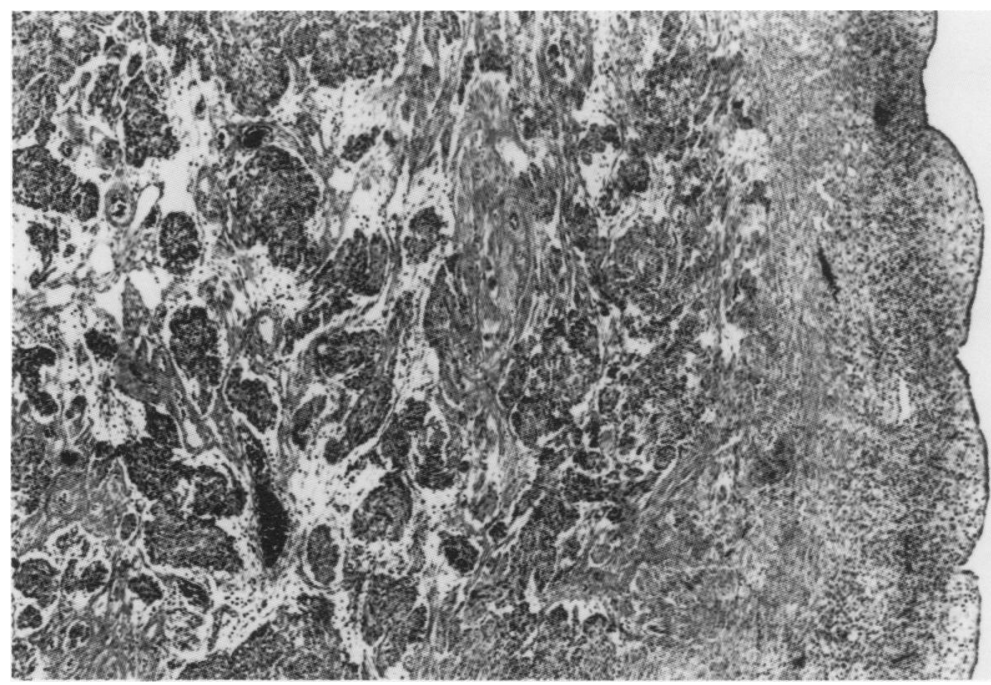

Figure 2 Degenerative changes in myometrium distant from discrete tumour masses (note endometrium on right). sent in the myometrium. On microscopy, the endometrium showed prominent decidual change. The larger fibroids showed "perinodular" degeneration (fig 1) with nodules of hypercellular smooth muscle separated by oedematous connective tissue and dilated thin-walled blood vessels. There was a sharp demarcation between degenerate leiomyoma and adjacent normal myometrium in some areas, but in many areas this demarcation was lost and perinodular degeneration involved the myometrium adjacent to the fibroids. Similar abnormality was present in myometrium distant from obvious leiomyoma masses (fig 2). No significant nuclear pleomorphism or mitotic activity was present and intravascular growth was not observed.

\section{Discussion}

Gonadotrophin releasing hormone analogues are used in the medical management of menorrhagia and for reducing leiomyoma volume before hysterectomy. The mode of action of these agents is not entirely clear, but the reduction in leiomyoma size is thought to be a result of the hypo-oestrogenic state induced by $\mathrm{GnRH}$ analogue administration. ${ }^{5}$ Degenerative changes including necrosis, haemorrhage, and hyaline degeneration have been described in leiomyomas following administration of GnRH analogues. ${ }^{1-4}$ Both a reduction $^{2}$ and an apparent increase ${ }^{1}$ in cellularity have been reported, the latter being regarded as an apparent increase resulting from condensation of atrophic smooth muscle cells rather than a genuine increase in cell number.

Perinodular hydropic degeneration within and adjacent to leiomyomas can result in appearances superficially resembling intravenous leiomyomatosis. ${ }^{6}$ This form of degeneration is probably responsible for the changes observed within the leiomyomas in the case reported here, but abnormalities were also presint in the myometrium distant from the leiomyomas and extended to the junction of endometrium and myometrium, resulting in appearances similar to diffuse leiomyomatosis. The presence of large discrete leiomyoma masses and substantial areas of normal myometrium, however, excludes this diagnosis. We propose that these abnormalities resulted from smooth muscle cell atrophy induced by $\mathrm{GnRH}$ analogue administration in combination with hydropic degeneration.

Degenerative and iatrogenic changes are likely to be encountered more often in myomectomy and hysterectomy specimens with increased use of $\mathrm{GnRH}$ analogues in the medical management of fibroids. It is important to recognise these abnormalities to avoid over-diagnosis of rare conditions such as intravenous or diffuse leiomyomatosis and to define completely the spectrum of histopathological changes associated with this form of treatment. 
1 Colgan TJ, Pendergast S, LeBlanc M. The histopathology of uterine leiomyomas following treatment with gonadotrophin releasing hormone analogues. Hum Pathol 1993; 24:1073-7.

2 Upadhyaya NB, Doody MC, Googe PB. Histopathological changes in leiomyomata treated with leuprolide acetate. Fertil Steril 1990;54:811-14.

3 Friedman AJ. Vaginal hemorrhage associated with degenerating submucous leiomyomata during leuprolide erating submucous leiomyomata during

4 Rein MS, Friedman AJ, Stuart JM, MacLaughlin DT.
Fibroid and myometrial steroid receptors in women treated with gonadotrophin-releasing hormone agonist

5 Friedman AJ, Barbieri RL, Benacerraf BR, Schiff I. Treatment of leiomyomata with intranasal or subcutaneous leuprolide, a gonadotrophin-releasing hormone agonist. Fertil Steril 1987;48:560-4.

6 Clement PB, Young RH, Scully RE. Diffuse, perinodular and other patterns of hydropic degeneration within and adjacent to uterine leiomyomas. Am f Surg Pathol 1992;16:26-32. 